\title{
We are the company we keep: The importance of the tumor microenvironment
}

\author{
Sai Yendamuri, MD, FACS
}

\author{
From the Department of Thoracic Surgery, Roswell Park Comprehensive Cancer Center, Buffalo, NY. \\ Disclosures: Author has nothing to disclose with regard to commercial support. \\ Received for publication June 17, 2018; revisions received June 17, 2018; accepted for publication June 18, 2018; \\ available ahead of print Aug 10, 2018. \\ Address for reprints: Sai Yendamuri, MD, FACS, Department of Thoracic Surgery, Roswell Park Comprehensive \\ Cancer Center, Elm and Carlton St, Buffalo, NY 14263 (E-mail: sai.yendamuri@roswellpark.org). \\ J Thorac Cardiovasc Surg 2018;156:1669 \\ $0022-5223 / \$ 36.00$ \\ Copyright (C) 2018 by The American Association for Thoracic Surgery \\ https://doi.org/10.1016/j.jtcvs.2018.06.061
}

That a lepidic component of an adenocarcinoma provides a favorable prognosis is well known. However, specific nuances of the presence of this tumor characteristic are still being explored and defined. Katsumata and colleagues ${ }^{1}$ provide another important association between this histologic characteristic and its biology.

Katsumata and colleagues ${ }^{1}$ assembled a sizable cohort of patients with adenocarcinoma with and without lepidic features undergoing a lobectomy or greater surgical resection. They then grouped these patients into 2 propensity scorematched cohorts (116 patients each) called Lepidic +ve and Lepidic - ve, based on a cutoff of $10 \%$ of the tumor having a lepidic component. They compared the clinical outcomes of these cohorts and then studied a subset of these tumors ( $\mathrm{T} 1 \mathrm{~b} ; \mathrm{n}=62$ in each group) with immunohistochemistry staining for 4 distinct biological aspects: the presence of cancer stem cells, tumor hypoxia, tumor invasiveness, and the presence of tumor- promoting stromal cells.

Although Katsumata and colleagues ${ }^{1}$ did not find statistically significant differences in overall or diseasespecific survival, they did find differences in two biological aspects-tumor hypoxia and the presence of tumor-promoting stromal cells.

The investigators performed the best possible study with a retrospective cohort and its inherent limitations. From the survival curves, it appears that the lack of differences in clinical outcomes is more a function of the size of the cohort and its attendant power issues rather than a true lack of difference. The real importance of the study, however, lies in the finding that the behavior of these early-stage tumors seem to be more dependent on the tumor microenvironment and the interaction of the tumor with the stroma than on inherent tumor aggressiveness. This principle has now emerged as an important determinant of tumor behavior and its subsequent outcomes. The tumor microenvironment is now known to play a role in tumor angiogenesis, ${ }^{2}$ protection of stem cells, ${ }^{3}$ and promotion of tumor metastasis. ${ }^{4}$ In addition to providing insights into tumor behavior this association has become increasingly associated with treatment response, ${ }^{5}$ with both chemotherapy as well as

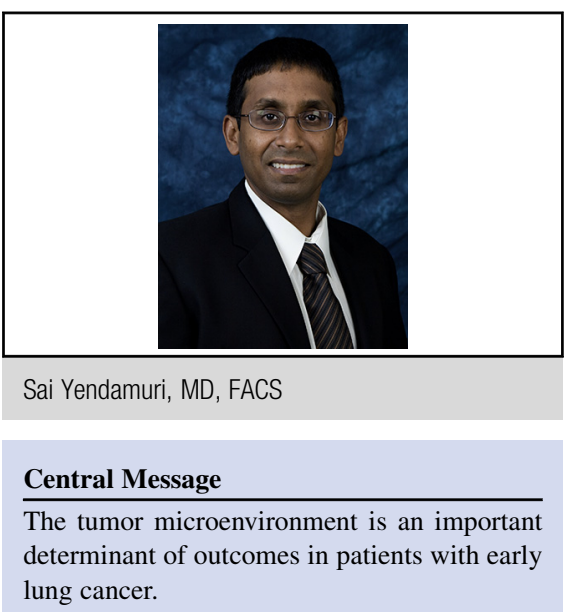

See Article page 1679 .

radiotherapy. ${ }^{6}$ For surgeons, this has become increasingly relevant as neoadjuvant treatments using emerging therapies enter the early lung cancer treatment domain. ${ }^{7}$ In particular, immunotherapy is heavily dependent on the tumor microenvironment and its interaction with the tumor. Future efforts will likely involve the modulation of this microenvironment to change tumor behavior in isolation as well as in response to interventions. This modulation is also likely to be achieved by molecules not considered chemotherapy today.

Katsumata and colleagues ${ }^{1}$ demonstrate that, in early lung cancers, the tumor microenvironment is probably as important as the tumor itself. Perhaps, as with human beings, the company cancer cells keep determines a significant portion of their behavior.

\section{References}

1. Katsumata S, Aokage K, o Miyoshi T, Tane K, Nakamura H, Sugano M, et al. Dif ferences of tumor microenvironment between stage I lepidic-positive and lepidicnegative lung adenocarcinomas. J Thorac Cardiovasc Surg. 2018;156:1679-88.

2. De Palma M, Biziato D, Petrova TV. Microenvironmental regulation of tumour angiogenesis. Nat Rev Cancer. 2017;17:457-74.

3. Relation T, Dominici M, Horwitz EM. Concise review: An (im)penetrable shield: how the tumor microenvironment protects cancer stem cells. Stem Cells. 2017;35:1123-30.

4. Riggi N, Aguet M, Stamenkovic I. Cancer metastasis: A reappraisal of its underlying mechanisms and their relevance to treatment. Annu Rev Pathol. 2018;13:117-40.

5. Haratani K, Hayashi H, Tanaka T, Kaneda H, Togashi Y, Sakai K, et al. Tumo immune microenvironment and nivolumab efficacy in EGFR mutation-positive non-small-cell lung cancer based on T790M status after disease progression during EGFR-TKI treatment. Ann Oncol. 2017;28:1532-9.

6. Hirata E, Sahai E. Tumor microenvironment and differential responses to therapy Cold Spring Harb Perspect Med. 2017;7(7).

7. Owen D, Chaft JE. Immunotherapy in surgically resectable non-small cell lung cancer. J Thorac Dis. 2018;10(Suppl 3):S404-11. 